\title{
ANALYTIC HIERARCHY PROCESS AND ACTIVITY B ASED COSTING TO COMPUTE THE COST OF COMPETENCIES: EVIDENCE FROM A CASE STUDY
}

\author{
Lorella Cannavacciuolo ${ }^{*}$, Luca Iandoli ${ }^{2}$, Cristina Ponsiglione ${ }^{3}$, Giuseppe Zollo ${ }^{4}$ \\ Dept. Business \& Management Engineering, Universita’ degli Studi Napoli Federico II \\ Piazzale Tecchio 80, 80125, Napoli, Italy \\ E-mail: ${ }^{1}$ lorella.cannavacciuolo@unina.it \\ ${ }^{2}$ luca.iandoli@unina.it \\ 3 cristina.ponsiglione@unina.it \\ ${ }^{4}$ giuseppe.zollo@unina.it
}

\begin{abstract}
The aim of the paper is to propose a methodology to compute the cost of competencies involved in critical organizational processes. We present a costing model for the assessment of competencies integrating a cost technique, Activity Based-Costing (ABC), with a Analytic Hierarchy Process (AHP). The proposed model has been tested in a small manufacturing firm operating in the packaging sector and the first results are reported. The main contribution of the work concerns the development of a costing model useful for managers to acquire awareness about the role of competencies in the activation of critical processes, and consequently, triggering learning processes. Furthermore, the evaluation of the costs of competencies can be used to make a more careful analysis of the cost/benefits ratio associated to an investment in intangible assets than the ones performed by other methods available in the literature that are unbalanced toward the evaluation of benefits.
\end{abstract}

Keywords: competence cost, organizational capability, Activity Based Costing, Analytic Hierarchy Process

\section{Indi vidual competencies as enabler of organi zational capabilities}

Traditionally, organizational assessment methodologies are aimed at evaluating training needs at the individual level (Spence and Spencer, 1993; Boyatzis, 1982) or the strategic value of core competencies at the company level (Teece, Pisano and Shuen, 1997; Prahalad and Hamel, 1990); in both cases, however, the estimation of the economic value of such assets is not considered. Though these approaches provide robust theoretical frameworks and assessment techniques, they do not deal with economic evaluation of investments in intangible assets. The literature on the evaluation of intangible assets has developed methods for economic evaluation, considering value creation process as a black box (Morris, 2001; Sveiby, 2001; Andriessen, Tiesen, 2000, Stewart, 1997). Such economic methods evaluate the intangible assets merely through aggregate evaluations of intangible inputs or outputs and, consequently, they are not able to estimate the contribution of specific intangible assets to value creation. In this paper we intend to contribute to fill this gap through the development of a model for the economic evaluation of individual competencies. The model has been designed to assess two components: the value generated by a competence within a given organizational capability and the cost of the competence. In this way the assessment of value and cost of competencies helps management to frame competencies management

\footnotetext{
* Corresponding author
} 
using tools in terms of an investment for the acquisition, development or maintenance of intangible assets. In the specific case of competencies, evaluating cost and value of a given competence means estimating i) acquisition/development and utilization costs of the competence, and (ii) the value produced by critical processes enabled by the competence. Prior works focused on the estimation of the value produced by competencies (Cannavacciuolo et al., 2009), while this paper presents a model to determinate the cost of individual competencies integrating a decision support technique (Analytic Hierarchy Process) with a costing technique (Activity Based Costing).

There is a key difference between our work and the aforementioned literature on competencies and intangible assets evaluation. Both for organizational assessment methodologies and economic evaluation of intangible assets models, the intangibles are resources, i.e. passive inputs of value creation processes. In particular, competencies are considered as attributes of human resources. Instead, we consider competencies as a very special kind of resource: they are skills and abilities of individuals able to activate other resources (personal, organisational and environmental) in different work situations in order to satisfy the expectations of internal and external customers (Capaldo, Iandoli and Zollo, 2006). Therefore, competencies represent dynamic resources able to exploit static resources in an action space structured by real or perceived environmental and organizational constraints.

Following the perspective of organizational capabilities theory (Teece, Pisano and Shuen, 1996), we consider competencies as knowledge in action activated and developed in critical organizational process. Namely, organizational capabilities are the result of the integration of one or more critical processes in which individual competencies of actors are activated into coherent action to deliver value for customers. For a high-tech company, for instance, the ability of rapidly updating its products through constant innovation and the addition of new functions is a capability inasmuch the speed of updating is perceived as a valuable distinctive characteristic by customers. Capabilities can give a competitive advantage only if there are not easily imitable by competitors.

The first conclusion emerging from the consideration above outlined are:

1. Critical processes are integrated into higher level organizational capability associated to critical dimensions of value for customers

2. a firm can "bundle" resources and support critical business processes through specific individual competencies able integrate different kind of resources;

3. resources, processes and individual competencies are linked by the activities through which competencies consume resources.

In this vision, individual competencies are the point of arrival of the link value-capability-processesactivities-resources. In this perspective it is not possible to reduce the calculation of the individual competencies cost to human resources' cost (wages, social security contributions, training and selection cost, and so on). The cost of the individual competencies have to include also costs relating to the other material and immaterial resources activated by competencies in the realization of activities and critical processes.

In the next section, we describe the costing model while in section 3 and 4 the case study, results and implications are presented.

\section{An integrated AHP-ABC costing model to compute individual competencies' costs} According to theoretical premises above outlined, the cost of competence arises from processes critical for value creation through the exploitation of material and immaterial resources. Therefore, the competence cost has to include both human resource and the material/immaterial resource costs. According to this perspective, we define the cost of competence exercise as the sum of human, material and immaterial resources activated by competencies to contribute to the realization of activities. In detail, total cost of competence ownership (TCCO) is made by the exercise cost plus recruitment cost plus training cost:

$$
\text { TCCO }=\text { recruitment cost }+ \text { training cost }+ \text { exercise cost }
$$


In particular, recruitment and training costs are obtained as sum of direct cost while the evaluation of exercise cost has to be performed with a technique able to trans late in quantitative terms the relationship between processes and competencies. The accounting technique Activity Based Costing (ABC) fits well this need as: i) it is a technique of cost analys is based on the concept of "process" and "activity"; ii) it makes it possible to determine the cost of an "object" on the basis of the activities necessary to its realization and of the resources that such activities use. In fact, as the competencies are responsible for the starting up of the organizational processes and of the activities they include, it can be deemed that the competencies, through these activities, consume different kinds of resources (material and immaterial ones) and for this reason they can be considered as a cost object. Starting from mapping organizational processes in order to identify resources, activities, competencies and their links, ABC calculates an object cost in function of the activities needed to object realization and of resources absorbed by activities. The resource costs are allocated to activities according to causal drivers (resource drivers). The total cost of activities, namely activity cost pool, is allocated to object through causal drivers (activity drivers). Summing all activities costs allocated, we obtain the object cost (fig 1).

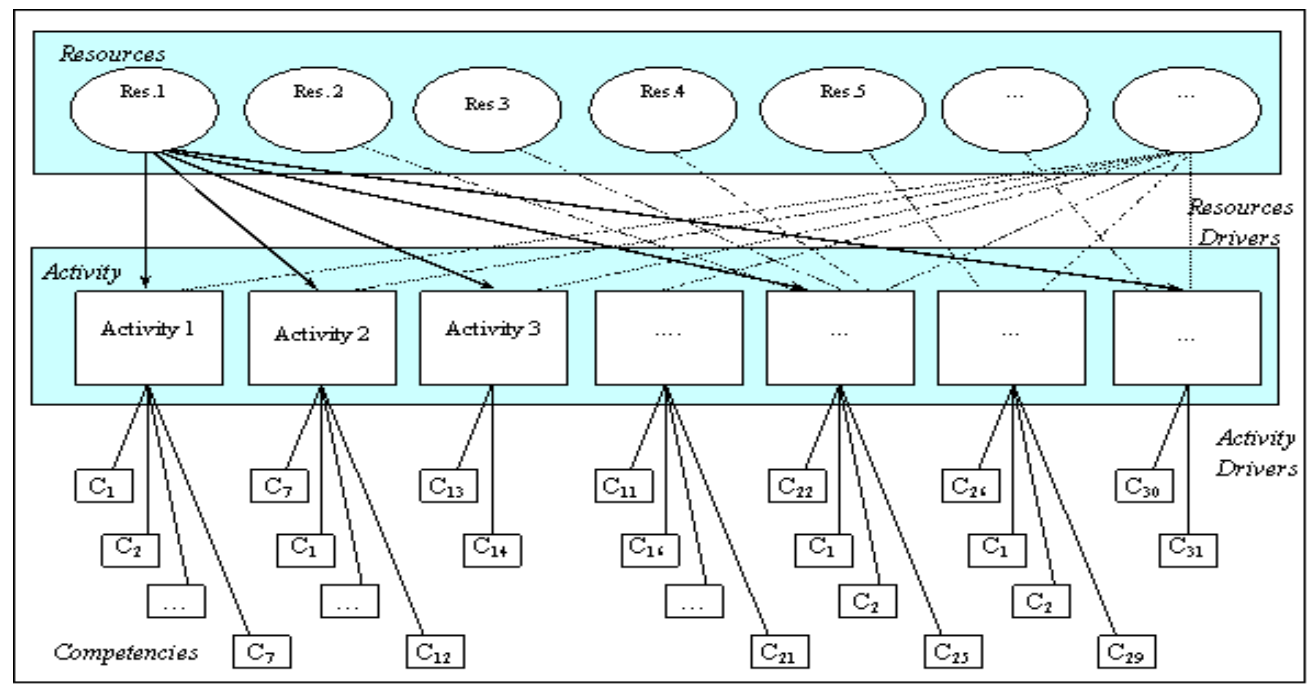

Figure 1. The ABC schema applied to competencies

Operatively, through the resource drivers, resources' cost is allocated to activities according to the following formula (2):

$$
\begin{gathered}
\mathrm{CA}(\mathrm{j})=\Sigma \mathrm{i}(1, \mathrm{n}) \mathrm{CR}(\mathrm{i}) \times \mathrm{RDij} \\
\mathrm{CA}(\mathrm{j})=\text { cost of } \mathrm{j} \text {-ism activity } \\
\mathrm{CR}(\mathrm{i})=\text { cost of } \mathrm{i} \text {-ism resource }
\end{gathered}
$$

Then, in the same way, through the activity drivers, the cost of the activity $\mathrm{Aj}$ is allocated to competencies as shown in the following formula:

$$
\begin{aligned}
& \mathrm{CC}(\mathrm{K})=\Sigma \mathrm{j}(1, \mathrm{~m}) \mathrm{CA}(\mathrm{j}) \mathrm{x} \text { ADkj } \quad \mathrm{k}=1,2, \ldots \ldots, 1 \\
& \mathrm{C} \mathrm{C}(\mathrm{K})=\text { cost of } \mathrm{k} \text {-ism competence } \\
& \mathrm{CA}(\mathrm{j})=\text { cost of } \mathrm{j} \text {-ism activity }
\end{aligned}
$$

$\mathrm{ADkj}=$ activity drivers between $\mathrm{j}$-ism activity and $\mathrm{k}$-ism competence

The costing model proposed is named integrated AHP-ABC costing model as AHP plays a role in the identification of activity drivers, the cause-effect relation related to the consumption of activities on the 
behalf of competencies, assuming that the impact of competencies on processes can be inferred by expert judgements. The application of AHP/ABC costing model is structured as following:

- calculating the costs of resources and the resource drivers;

- calculating activity drivers through the application of AHP;

- calculating competencies' costs.

A phase of mapping of organizational capability and competencies involved is preliminary to implement the ABC-AHP costing model. A brief description of this phase is presented in the case study which focuses on application of $\mathrm{ABC}$-AHP costing model and discussion on results.

\section{Implementation of $\mathrm{ABC}$ - $\mathrm{AHP}$ costing model: a case study}

The ABC-AHP costing model has been applied to a small company, here named company Alfa for privacy concerns, producing packaging for pharmaceutical products. The company management is evaluating the opportunity to introduce a new technology based on an innovative software package capable to reduce the production time and the number of rejected products. The implementation of such software requires the acquisition of competencies, new or with higher specialization, currently not available to the company. In order to evaluate the investment in the new technology, the management has to assess the value of the benefit obtainable from the implementation in terms of the cost reduction and the cost of its acquisition, implementation and management. Because of room limitation, in the following section we show only how the cost of current competencies can be calculated. The cost of investment is inferred by comparison between the costs of current competencies and the costs of competencies needed to exploit the opportunity, which is also computed through AHP-ABC costing model. To apply the AHP$\mathrm{ABC}$ costing model, the research group mapped the capability of Alfa identifying the process and its activities and the competencies involved. The mapping phase has been performed through interviews to key actors and field observation. The organizational capability on which we focus is the diversification of products portfolio to expand the range of products and have more flexible supply capability to respond promptly to customers' requests. Then, we analyzed the processes associated to the capability, in this case the productive process, identifying the activities. The productive process is broken into the activities: design, fine-tuning, layout design, maintenance, quality control, machine conduction, products and materials handling. Through interviews to production manager, the competencies involved in each activities are been identified. The competencies have been classified according to two level of specialization: basic and specialized.

Once the mapping phase has been completed, the resources needed and their costs are inferred by interviews and account book consultation and the resource drivers are easily identified to allocate the resources' costs to activities (see (2)). The activities drivers have been calculated through the individuation of the importance of each competency on the realization of the activity. The importance of a competence on activity realization is expressed by a weigh that reflect the judgment of experts. The weights have been calculated by AHP. The scale used to apply AHP goes from 1 to 9 where 1 is equally importance and 9 is absolutely more important. Finally, through the activity drivers the cost of competencies is calculated (see (3)).

Focusing on the design activity whose cost is $€ 3678$, there are 7 competencies involved whose weight are showed in table 1 .

Table 1: Activity drivers for design activity computing through AHP

\begin{tabular}{|c|c|c|}
\hline \multicolumn{3}{|c|}{ Design activity } \\
\hline \multicolumn{3}{|c|}{ Competencies on } \\
\hline Activity Drivers & & Competencies cost \\
\hline $\mathrm{C} 1$ traditional injection process & 0.02 & $€ 73,56$ \\
\hline C2 material & 0.31 & $€ 1.140,18$ \\
\hline
\end{tabular}




\begin{tabular}{|lc|c|}
\hline C3 press elements & 0.14 & $€ 514,92$ \\
\hline C4 channel control junction box & 0.03 & $€ 110,34$ \\
\hline C5 press materials & 0.05 & $€ 183,90$ \\
\hline C6 technical characteristics of product & 0.32 & $€ 1.176,96$ \\
\hline C7 machine & 0.13 & $€ 478,14$ \\
\hline
\end{tabular}

Considering the competence $\mathrm{C} 1$ on traditional injection process, its costs is the sum of four items related to four activities in which the competence is involved (design, fine-tuning, quality control, machine conduction) and it is equal to $€ 51321$ ( $21 \%$ of the process cost). In the same way, it is possible to compute the costs of all competencies involved in the processes. Table 2 shows the competencies involved and their costs.

Table 2: Cost of competencies computed through AHP-ABC costing model

\begin{tabular}{|l|c|}
\hline \multicolumn{2}{|c|}{ Competencies on productive process } \\
\hline Competency & Cost \\
\hline Quality requirements on materials and product & $€ 65.177,00$ \\
\hline Traditional injection process & $€ 51.321,00$ \\
\hline Operative flow & $€ 45.161,00$ \\
\hline Press elements & $€ 22.404,00$ \\
\hline Pallet truck & $€ 16.839,00$ \\
\hline Machine & $€ 16.685,00$ \\
\hline Materials & $€ 14.385,00$ \\
\hline Quality (visual manufacturing faults) & $€ 3.274,00$ \\
\hline Equipments existing on market & $€ 2.878,00$ \\
\hline Suction system & $€ 2.878,00$ \\
\hline Administrative procedure for materials handling & $€ 1.871,00$ \\
\hline Mechanical manufacturing & $€ 1.336,00$ \\
\hline Press materials & $€ 1.177,00$ \\
\hline Compressor & $€ 505,00$ \\
\hline Technical characteristics of product & $€ 478,00$ \\
\hline Press & $€ 353,00$ \\
\hline Temperature controllers & $€ 353,00$ \\
\hline Fridges & $€ 252,00$ \\
\hline Quality norms & $€ 208,00$ \\
\hline Channel control junction box & $€ 183,00$ \\
\hline Total cost of productive process & $€ 247.718,00$ \\
\hline
\end{tabular}

The AHP technique is not only necessary for the $\mathrm{ABC}$ application but it allows to identify the critical competencies both in an activity and in the whole process. In the case of activity design, the competencies $\mathrm{C} 6$ and $\mathrm{C} 2$ are the more critical while the competencies $\mathrm{C} 1, \mathrm{C} 2$ e $\mathrm{C} 5$ have an marginal impact on activity realization.

\section{Conclusion and implications}

The case study provides some insights on how this model can be used to improve business processes analysis. First of all, the main output of the costing model is the computation of costs of competencies. This information, integrated with value information, is fundamental to carry out the evaluation of investment in competencies. From a strategic prospective, the application of AHP-ABC costing model 
can help the manager to look into the process, making them more conscious about competencies involved in each activity and their impact on value creation. The decision on disinvestment or maintenance of critical competencies are more sensitive compared to other competencies. In the case study, it emerges that there are only 4 critical competencies whose costs represent the $75 \%$ of the total costs (table 2 ). In this perspective, analytic techniques, such as AHP and ABC, play a supporting role in the discovery of the organizational key processes.

The paper present some limitations. First, the methodology has been applied to a very simple case study in which the description of processes and competencies is rather straightforward. In more complex case, organizational analys is could be more cumbersome and time-consuming. A certain degree of subjectivity is present in the map of capabilities needed to perform distinctive characteristics and the activities drivers as evaluated through expert judgments. These limitations may affects the reliability of competencies cost. In this perspective, further researches could carry out to purify expert opinion from bias.

\section{REFERENCES}

Amit, R., Schoemaker, P.J.H. (1993). Strategic Assets and Organizational Rent. Strategic Management Journal Vol.14, 33-46.

Andriessen, J., Tiessen, P. (2000), Weightless Weight-Find your real value in a future of intangibles assets. London, Pearson Education

Barney J.B. (1991). Firm Resources and Sustained Competitive Advantage, Journal of Management Vol. $17,99-120$.

Boyatzis, R.E. (1982). The Competent Manager. Wiley, New York.

Cannavacciuolo, L., Iandoli, L., Ponsiglione, C., Zollo, G. (2009). Competencies as Options: Determining Competencies Economic. Journal of Financial Decision Making, Volume 5, Number 2, pp. 29-42.

Capaldo, G., Iandoli, L., Zollo, G. (2006). A situationalist Perspective to Competencies Management', Human Resource. Management Journal, 45(3), 429-448.

Grant, R.M. (1991). The Resource-Based Theory of Competitive Advantage: Implications for Strategy Formulation. California Management Review, Spring, $114-135$.

Morris M.R. (2001), Intangible Assets and their role in Corporate Value, Irving, Value Incorporated.

Prahalad, C.K., Hamel, G. (1990). The Core Competence of the Corporation, Harvard Business Review, May-June, 79-91.

Saaty, T.L., (1980). The Analytic Hierarchy Process. New York: McGraw-Hill

Spencer, L.M., Spencer, S.M. (1993). Competence at Work. Wiley, New York, 1993).

Sveiby K. (2001), Methods for Measuring Intangible Assets, www.sveiby.konverge.com/articles.

Teece, D.J., Pisano, G. e Shuen, A. (1997). Dynamics capabilities and strategic management, Strategic Management Journal, 18(7), 509-533. 